\title{
ERS guidelines on the diagnosis and treatment of chronic cough in adults and children
}

\author{
Alyn H. Morice ${ }^{1}$, Eva Millqvist ${ }^{2}$, Kristina Bieksiene ${ }^{3}$, Surinder S. Birring ${ }^{4,5}$, \\ Peter Dicpinigaitis ${ }^{6}$, Christian Domingo Ribas ${ }^{7}$, Michele Hilton Boon $\mathbb{0}^{8}$, \\ Ahmad Kantar (10) ${ }^{9}$, Kefang Lai ${ }^{10,21}$, Lorcan McGarvey ${ }^{11}$, David Rigau ${ }^{12}$, \\ Imran Satia ${ }^{13,14}$, Jacky Smith ${ }^{15}$, Woo-Jung Song (10 16,22, Thomy Tonia ${ }^{17}$, Jan W. \\ K. van den Berg ${ }^{18}$, Mirjam J.G. van Manen ${ }^{19}$ and Angela Zacharasiewicz ${ }^{20}$
}

@ERSpublications

New ERS guideline on chronic cough details the paradigm shift in our understanding. In adults, cough hypersensitivity has become the overarching diagnosis, and in children, persistent bacterial bronchitis explains most wet cough, changing treatment advice. http://bit.ly/2kycX8D

Cite this article as: Morice AH, Millqvist E, Bieksiene $\mathrm{K}$, et al. ERS guidelines on the diagnosis and treatment of chronic cough in adults and children. Eur Respir J 2020; 55: 1901136 [https://doi.org/10.1183/ 13993003.01136-2019].

ABSTRACT These guidelines incorporate the recent advances in chronic cough pathophysiology, diagnosis and treatment. The concept of cough hypersensitivity has allowed an umbrella term that explains the exquisite sensitivity of patients to external stimuli such a cold air, perfumes, smoke and bleach. Thus, adults with chronic cough now have a firm physical explanation for their symptoms based on vagal afferent hypersensitivity. Different treatable traits exist with cough variant asthma (CVA)/eosinophilic bronchitis responding to anti-inflammatory treatment and non-acid reflux being treated with promotility agents rather the anti-acid drugs. An alternative antitussive strategy is to reduce hypersensitivity by neuromodulation. Low-dose morphine is highly effective in a subset of patients with cough resistant to other treatments. Gabapentin and pregabalin are also advocated, but in clinical experience they are limited by adverse events. Perhaps the most promising future developments in pharmacotherapy are drugs which tackle neuronal hypersensitivity by blocking excitability of afferent nerves by inhibiting targets such as the ATP receptor (P2X3). Finally, cough suppression therapy when performed by competent practitioners can be highly effective. Children are not small adults and a pursuit of an underlying cause for cough is advocated. Thus, in toddlers, inhalation of a foreign body is common. Persistent bacterial bronchitis is a common and previously unrecognised cause of wet cough in children. Antibiotics (drug, dose and duration need to be determined) can be curative. A paediatric-specific algorithm should be used.

This document was endorsed by the ERS Executive Committee on 26 August, 2019.

The guidelines published by the European Respiratory Society (ERS) incorporate data obtained from a comprehensive and systematic literature review of the most recent studies available at the time. Health professionals are encouraged to take the guidelines into account in their clinical practice. However, the recommendations issued by this guideline may not be appropriate for use in all situations. It is the individual responsibility of health professionals to consult other sources of relevant information, to make appropriate and accurate decisions in consideration of each patient's health condition and in consultation with that patient and the patient's caregiver where appropriate and/or necessary, and to verify rules and regulations applicable to drugs and devices at the time of prescription.

This article has supplementary material available from erj.ersjournals.com.

This article has been revised according to the correction published in the November 2020 issue of the European Respiratory Journal; republished January 2021 to correct an author affiliation.

Received: 24 May 2019 | Accepted after revision: 01 Aug 2019

Copyright @ERS 2020 


\section{Introduction}

Cough is a vital protective reflex preventing aspiration and enhancing airway clearance. However, pathologically excessive and protracted cough is a common and disabling complaint, affecting perhaps 5$10 \%$ of the adult population [1]. When severe, it causes a major decrement in the quality of life, with comorbidities such as incontinence, cough syncope and dysphonia leading to social isolation, depression and difficulties in relationships [2].

While a wide range of diseases may be associated with chronic cough, it has become increasingly clear that the majority of adult patients presenting with chronic cough as the primary complaint have a common clinical presentation [3]. They often complain of exquisite sensitivity to inhalation of environmental irritants such as perfumes, bleaches and cold air which result in sensations of tickling/irritation in the throat and an urge to cough; features suggestive of heightened sensitivity of the neuronal pathways mediating cough [4]. In addition, there is a unique epidemiology with two-thirds of patients being female and the peak prevalence in the fifties and sixties. These observations have led to the concept of cough hypersensitivity syndrome as a diagnosis [5]. In children, chronic cough presents in a markedly different fashion with different aetiology. They are not miniature adults [6].

This guideline aims to improve diagnostic accuracy and promote evidence-based therapy for both paediatric and adult patients in both primary and secondary care. The guideline is intended for use by all healthcare professionals looking after patients with chronic cough. The guideline has been developed by a multidisciplinary international panel of clinicians and scientists with a published record of expertise in the field. Input on patient views and preferences was sought via the European Lung Foundation who provided an advisory group of patient representatives who expressed their preferences via teleconferences, attendance at the European Respiratory Society (ERS) congress, and in writing. They contributed to formulating and prioritising the key questions.

\section{Guideline scope and structure}

This guideline follows the hybrid model of the ERS Guidelines Working Group and Science Council [7], which combines the scientific rigour of the Grading of Recommendations, Assessment, Development and Evaluations (GRADE) framework for key questions of uncertainty with a narrative component to reflect the expert consensus of the guideline task force. The narrative covers clinically important aspects of chronic cough, while the eight key questions systematically explore the evidence in areas of clinically important controversy.

Full details of the methodological process and the analysis of the individual questions can be found in the supplementary material. Table 1 provides a summary of the eight questions (two diagnostic and six therapeutic questions), the level of evidence and the recommendations arising from the systematic review. All other propositions should be regarded as narrative statements.

Affiliations: ${ }^{1}$ Respiratory Research Group, Hull York Medical School, University of Hull, Hull, UK. ${ }^{2}$ Dept of Internal Medicine/Respiratory Medicine and Allergology, Sahlgrenska University Hospital, University of Gothenburg, Gothenburg, Sweden. ${ }^{3}$ Dept of Pulmonology, Lithuanian University of Health Sciences, Kaunas, Lithuania. ${ }^{4}$ Centre for Human and Applied Physiological Sciences, School of Basic and Medical Biosciences, Faculty of Life Sciences and Medicine, King's College London, London, UK. ${ }^{5}$ Dept of Respiratory Medicine, King's College Hospital, London, UK. ${ }^{6}$ Albert Einstein College of Medicine, Montefiore Medical Center, Bronx, NY, USA. ${ }^{7}$ Pulmonary Service, Corporació Sanitària Parc Taulí (Sabadell), Dept of Medicine, Universitat Autònoma de Barcelona (UAB), Barcelona, Spain. ${ }^{8} \mathrm{MRC} / \mathrm{CSO}$ Social and Public Health Sciences Unit, University of Glasgow, Glasgow, UK. ${ }^{9}$ Pediatric Cough and Asthma Center, Istituti Ospedalieri Bergamaschi, University and Research Hospitals, Bergamo, Italy. ${ }^{10}$ Dept of Clinical Research, State Key Laboratory of Respiratory Disease, Guangzhou Institute of Respiratory Health, First Affiliated Hospital of Guangzhou Medical University, Guangzhou, China. ${ }^{11}$ Centre for Experimental Medicine, School of Medicine, Dentistry and Biomedical Sciences, Queen's University Belfast, Belfast, UK. ${ }^{12}$ Iberoamerican Cochrane Centre, Barcelona, Spain. ${ }^{13}$ Dept of Medicine, Division of Respirology, McMaster University, Hamilton, ON, Canada. ${ }^{14}$ University of Manchester, Division of Infection, Immunity and Respiratory Medicine, Manchester Academic Health Science Centre, Manchester, UK. ${ }^{15}$ University of Manchester, Division of Infection, Immunity and Respiratory Medicine, Manchester University NHS Foundation Trust, Manchester, UK. ${ }^{16}$ Airway Sensation and Cough Research Laboratory, Dept of Allergy and Clinical Immunology, Asan Medical Center, University of Ulsan College of Medicine, Seoul, Korea. ${ }^{19}$ Institute of Social and Preventive Medicine, University of Bern, Bern, Switzerland.

${ }^{18}$ Dept of Respiratory Medicine, Hoestpoli Isala hospital, Zwolle, The Netherlands. ${ }^{19}$ Dept of Respiratory Medicine, Erasmus University Medical Center, Rotterdam, The Netherlands. ${ }^{20}$ Dept of Pediatrics, Teaching Hospital of the University of Vienna, Wilhelminen Hospital, Vienna, Austria. ${ }^{21}$ Representing the Chinese Thoracic Society. ${ }^{22}$ Representing the Asia Pacific Association of Allergy, Asthma and Clinical Immunology (APAAACI).

Correspondence: Alyn H. Morice, Hull York Medical School, University of Hull, Respiratory Research Group, Castle Hill Hospital, Castle Road, Cottingham, East Yorkshire, HU16 5JQ, UK. E-mail: a.h.moriceahull.ac.uk 
TABLE 1 Table of recommendations, strength and level of evidence, and supporting remarks

\section{Strength of Level of Values and preferences Remarks \\ recommendation evidence}

Question 1: should chest CT scan be routinely performed on chronic cough patients with normal chest radiograph and physician examination?

Recommendation 1: we suggest Conditional Very low This recommendation places

that clinicians do

perform a chest

pertients wi

patients with chronic cough

who have a normal chest

radiograph and physical

examination. relatively highe and outcomes including adverse events from radiation exposure. Lower value was given to diagnostic sensitivity and specificity. impact on patient management

\section{Question 2: should $F_{\mathrm{eN}} /$ blood
Recommendation 2: researc recommendation.}

\author{
Very low
}

resp vaces a predictability for the treatment response and the impact on the treatment decision. Lower value was given to diagnostic sensitivity and specificity.
In chronic cough patients with normal chest radiographs and physical examination, rates of any positive findings on chest CT scan varied widely in the literature. However, the task force members found that these abnormalities were unlikely to explain cough and may not influence management of the patients.

For those patients without a clear diagnosis or a chronic cough that is refractory to treatment of associated conditions, a high-resolution CT scan of the chest may identify subtle interstitial lung disease not visible on chest radiographs, e.g. pulmonary fibrosis, hypersensitivity pneumonitis and bronchiectasis, or areas of mucus plugging, which may prompt the need for bronchoscopy for clearance, lavage and culture. However, whether these subtle changes are the cause of the cough or a consequence of an underlying condition, such as recurrent aspiration, is unknown.

There is a concern about potential cancer risk from CT radiation exposure [89]. According to an estimation study [88], a projected number of future cancers that could be related to chest CT scans performed in the US was 4100 (95\% uncertainty limits 1900-8100) cases from 7100000 scans, and the estimated rates were higher in children and females.

\section{chronic cough?}

There is a need for convenient, safe, and practical tests for detecting and predicting anti-inflammatory treatment responses in chronic cough. In randomised controlled trials of patients with different respiratory conditions, $F_{\mathrm{eNO}}$ or blood eosinophil levels were positively associated with anti-inflammatory treatment responses [133-135]. However, there is no high-quality evidence to guide the use of $F_{\mathrm{eNO}}$ or blood eosinophil counts as treatment response predictors in patients with chronic cough. In addition, there are still no optimal cut-off levels determined for the use in chronic cough populations.

Question 3: should anti-asthmatic drugs (anti-inflammatory or bronchodilator drugs) be used to treat patients with chronic cough?

Recomm should anti-asthmatic drugs lanti-inflammatory or bronchodilator drugs) be used to treat pat Conditional

Low This recommendation is based on the higher value of the clinical benefits from ICS in some patients with asthmatic cough lor airway eosinophilic inflammation) and lower value of adverse events.
Asthmatic cough (CVA and eosinophilic bronchitis) is a frequent phenotype of chronic cough. Evidence for ongoing airway eosinophilic inflammation can be collected by performing differential cell counts on samples from sputum induction or bronchoalveolar lavage; however, these tests are not available at most clinics. Moreover, there is no high-quality evidence for the routine use of $F_{\mathrm{eNO}}$ or blood eosinophil counts in patients with chronic cough las recommendation 2). Therefore, empirical therapy for asthmatic cough may be considered.

In the literature, there is a heterogeneity in the efficacy of ICS in adult patients with chronic cough. The variability in the treatment response is probably primarily related to patient characteristics, particularly eosinophilic inflammation.

Available evidence suggests that a high dose of ICS might be more effective than low-to-moderate dose regimen, as an empirical trial.

A treatment response is usually seen within 2-4 weeks. Thus, the empirical trial should be stopped if there is no response within 2-4 weeks.

The task force members were concerned about long-term overuse of ICS in the absence of evidence or treatment response. In addition, they were concerned about pneumonia in relation to fluticasone use in patients comorbid with COPD. 


\section{Strength of Level of Values and preferences Remarks}

\section{recommendation evidence}

Recommendation 3b: we suggest a short-term ICS trial (2-

chronic dry cough.

Recommendation 3c: we sugges a short-term antileukotriene trial (2-4 weeks) in adults with chronic cough, particularly in those with asthmatic cough.

Recommendation 3d: we suggest a short-term trial (2-4 weeks) of ICS and long-acting

bronchodilator combination in adults with chronic cough and fixed airflow obstruction.

Question 4: should anti-acid drugs (PPI

Recommendation 4: we suggest that clinicians do not routinely use anti-acid drugs in adult patients with chronic cough.
4 weeks) in children with
Conditional

Low

This recommendation is based on a higher value of the clinical benefits from ICS in some

patients with asthmatic cough (or eosinophilic inflammation) and a lower value of adverse events.

Conditional Low This recommendation is based on a higher value of the clinical benefits from antileukotrienes in some patients with asthmatic cough lor airway eosinophilic inflammation) and a lower value of adverse events.

Conditional Moderate This recommendation is based on a higher value of the clinical benefits from ICS and long-acting bronchodilator combination in some patients with COPD and a lower value of

ation is based on a higher value of the clinical benefits from anti-acid drugs only in some patients with acid reflux and a lower value of adverse events. adverse events.

Overall remarks are the same as those in adults.

The empirical trial should be stopped if there is no response within $2-4$ weeks.

Overall remarks are similar to those for ICS.

Currently, clinical evidence is only available in specific subgroups of patients, such as CVA or atopic cough. Overall efficacy of leukotriene receptor antagonist in nonspecific chronic cough patients is uncertain.

The empirical trial should be stopped if there is no response within $2-4$ weeks.

There is a concern about pneumonia in relation to fluticasone use in patients comorbid with COPD.

The empirical trial should be stopped if there is no response within $2-4$ weeks.

Anti-acid drugs are unlikely to be useful in improving cough outcomes, unless patients have peptic symptoms or evidence of acid reflux.

Clinical benefits from PPI over placebo on cough outcomes are not significant in patients without acid reflux and only modest in those with acid reflux. These agents effectively block gastric acid production and relieve acid-related symptoms, but have little effect on the number and volume of reflux events. Gastric acid does not appear to play a major role in the aetiology of chronic cough.

PPIs are mostly considered to be well tolerated. However, there is a potential concern about increased risks of complications, such as pneumonia, iron deficiency, vitamin $\mathrm{B}_{2}$ deficiency, small intestinal bacterial overgrowth, Clostridium difficile-associated diarrhoea or bone fracture [118].

Question 5: should drugs with promotility activity (reflux inhibitors, prokinetics and macrolides with promotility activity) be used to treat patients with chronic cough?

Recommendation 5: there is currently insufficient evidence to recommend the routine use of macrolide therapy in chronic cough. A 1-month trial of macrolides can be considered in the cough of chronic bronchitis refractory to other therapy, taking into account local guidelines on antimicrobial stewardship.
Conditional

Low This recommendation is based on a higher value of the clinica benefits from drugs with promotility activity only in some patients with chronic bronchitis and lower value of adverse events.
Current evidence only supports the use of azithromycin in patients with chronic bronchitis phenotype. However, mechanisms of azithromycin in improving cough outcomes are suggested to include prokinetic effects [136].

Since oesophageal dysmotility is a frequent finding in chronic cough patients, promotility agents such as metoclopramide, domperidone and azithromycin might be considered, although the clinical trial evidence in cough is sparse. 


\section{TABLE 1 Continued}

\section{Strength of Level of Values and preferences Remarks \\ recommendation evidence}

Question 6: Which cough neuromodulatory agents (pregabalin, gabapentin, tricyclics and opiates) should be used to treat patients with chronic cough?
Recommendation 6a: we Strong Moderate This recommendation is based on Agents acting directly on cough hypersensitivity

recommend a trial of low-dose

morphine (5-10 mg twice daily)

in adult patients with chronic

refractory cough.

Strong Moderate This recommendation is based on

a higher value of the clinica

benefits and adverse events

from opiates for chronic

refractory cough.

\section{Conditional}

Low

a trial of gabapentin or

pregabalin in adult patients

with chronic refractory cough.

Question 7: should nonpharmacolo Recommendation 7: we suggest a trial of cough control therapy in adult patients with chronic cough.

Conditional Moderate $\begin{aligned} & \text { This recommendation is based on } \\ & \text { a higher value of the clinical } \\ & \text { benefits from cough control } \\ & \text { therapy in chronic refractory } \\ & \text { cough, but places lower value } \\ & \text { on adverse events. }\end{aligned}$

his recommendation is based on a higher value of the clinical benefits and adverse events from gabapentin in chronic refractory cough.

政 hypersensitivity is a promising strategy for future developments. Current agents have been shown to be effective, but the side-effect profile is significant and may be mitigated by the use of lower doses than that used to treat pain.

Clinical experience suggests that only a proportion of patients lapproximately half respond to opiates. In responders, treatment response is very rapid and clear lusually seen in a week). Thus, discontinuation is recommended if there is no response in 1 or 2 weeks.

Codeine is generally not recommended (except where it is the only available opiate) due to interindividual genetic variability in drug metabolism (CYP2D6) and consequent less predictable treatment response and side-effect profile, particularly in children.

Clinical experience suggests the response rates of gabapentin and pregabalin are lower than that of opiates, and adverse events are more common. Common adverse effects are blurred vision, disorientation, dizziness, dry mouth, fatigue and nausea.

hronic cough?

Multi-component physiotherapy/speech and language therapy interventions may be considered for short-term improvement of health-related quality of life and cough frequency in patients with refractory chronic cough or who wish an alternative to drug treatment. However, this is a complex intervention that requires further study to determine which components are of value. Thus, experienced practitioners should undertake cough-directed physiotherapy and speech and language therapy intervention. The pool of individuals qualified for cough control therapy is currently lacking in many countries and should be increased.

\section{Question 8: should a trial of antibiotics be used in children with chronic wet cough with normal chest radiography, normal spirometry and no warning signs?}

Recommendation 8: we suggest Conditional Low This recommendation is based on Protracted bacterial bronchitis is a common treatable trait in children. Preferred antibacterial, a trial of antibiotics in children

a higher value of the clinical

benefit from antibiotics in dose and duration of therapy is unknown.

with chronic wet cough with

chronic wet cough, but a lower

Signs and symptoms suggestive of specific disease should always be investigated.

normal chest radiographs, value of adverse events.

$$
\text { warning signs. }
$$

CT: computed tomography; $F_{\text {eNo: }}$ exhaled nitric oxide fraction; ICS: inhaled corticosteroids; PPI: proton-pump inhibitor; $\mathrm{H}_{2}$ : histamine; CVA: cough variant asthma; COPD: chronic obstructive pulmonary disease. 
These guidelines were constructed with editorial independence from the ERS. Conflicts of interest were disclosed and statements can be found in the relevant section at the end of this article.

\section{Definition of chronic cough}

To define a chronic cough on the basis of longevity is clearly an arbitrary paradigm. Early studies used 3 months based on the Medical Research Council definition of chronic bronchitis [8]. More recent guidelines have adopted 8 weeks in adults [9] and 4 weeks in children [10]. Inclusion criteria for studies of novel antitussives require a cough refractory to treatment to be present for over a year. While some patients cough on a daily basis over many years, for others the disease has a relapsing and remitting course, making a definition based purely on a temporal basis difficult to sustain. The diagnosis of chronic cough should be made on a global clinical assessment taking into account the other features of the phenotypes of cough detailed below. The failure to recognise that the patient is suffering from the syndrome of chronic cough may lead to misdiagnosis with the patient labelled as suffering from recurrent chest infections, treatment resistant asthma or exacerbations of chronic obstructive pulmonary disease (COPD).

The commonly used definition of chronic cough in children is 4 weeks, although cough in children lasting $3-8$ weeks has been termed prolonged acute cough $[10,11]$. Irrespective of the exact duration, chronic cough in children is different from that in adults due to differences in the airway morphology, a higher degree of vulnerability to noxious insults, reduced control of the cough reflex and differences in maturation of the neurological and immunological system in the different paediatric age groups [6]. Chronic cough in children is best seen as a symptom of an underlying disease.

\section{Epidemiology}

Cough is a common medical problem and the socioeconomic burden is substantial [12]. However, there are no precise data on the burden of chronic cough, probably because chronic cough was previously perceived not as a clinical entity but as the consequent symptom from other respiratory conditions. There is no agreed definition of chronic cough for use in epidemiological studies [8].

A meta-analysis estimated the global prevalence of chronic cough in the general adult population as $\sim 10 \%$ [1]. It was more prevalent in Europe, America and Oceania than in Asia and Africa. Notably, the prevalence of chronic cough in adults is associated with a number of characteristics [13-16]. In a recent international survey of 10032 adult patients attending specialist cough clinics, two-thirds were female and the most common age for presentation was in the sixth decade [3]. The distinct demographic pattern is thought to be related to sex differences in central processing of cough sensation. The most commonly associated conditions are irritable bowel syndrome, obesity and a variety of neuropathic syndromes. Iatrogenic chronic cough from drug treatments is frequently unrecognised.

Approximately $35 \%$ of preschool children report cough at any given time in a month [17]; however, so far, no studies have systematically compared the prevalence of chronic cough in children worldwide. Reports of chronic cough in populations vary between $1 \%$ in India [18], 9\% in Eastern Europe [19] and 5-12\% in China, with increases in areas with higher air pollution [20]. Subjective perception and parental reporting of symptoms further biases prevalence reports [21]. Studies comparing prevalence rates worldwide are warranted.

\section{Impact on patients}

Chronic cough is highly disruptive to the individual affected and those around them. The most common reasons why patients with cough seek medical attention include concern about a serious underlying illness, vomiting, exhaustion, sleep disruption, social embarrassment, difficulty speaking on the telephone, urinary incontinence and annoyance to family, friends and workmates [22].

The consequence of chronic cough is a wide range of complications of coughing [23]. Most impactful on health-related quality of life (HRQoL) are stress urinary incontinence, interference with speech, and depression [24]. However, there are many others that can be equally bothersome, such as syncope. Individuals report, on average, eight adverse symptoms associated with cough [22].

Stress urinary incontinence is particularly impactful, as cough affects females disproportionately compared to males. Female patients with cough and urinary incontinence have worse HRQoL compared to those without incontinence [24]. In a quarter of patients, the incontinence is severe but rarely discussed. Thus incontinence should be enquired about during a consultation.

The impact of cough can be assessed and quantified formally with validated HRQoL tools, such as the Leicester Cough Questionnaire (LCQ) or the Cough-specific Quality of Life Questionnaire (CQLQ) [25, 26]. A strength of cough HRQoL tools is that they can be used to demonstrate the efficacy of antitussive 
therapy that is clinically meaningful. In the clinic simply asking "score your cough out of 10 " is perhaps the easiest subjective measure of treatment success [27] and should be asked at each consultation.

In children, the caregiver's worries about the underlying reason for the cough are a major driver to seek medical attention [28]. Paediatric cough is best considered as a symptom of an underlying disease. Therefore, the burden of disease is influenced by the quality of the healthcare system as well as healthcare independent factors such as age range [29-31], sex and indoor and outdoor air pollution [32].

\section{Aetiology and mechanisms}

Cough is a vital protective reflex preventing aspiration into the lung. Patients with a poor cough reflex such as those who suffer from neurological conditions succumb to recurrent episodes of aspiration [33] frequently misdiagnosed as "chest infections". Cough is a vagal reflex evoked by stimulation of afferents carried by the tenth cranial nerve, with their receptive fields primarily in the larynx and conducting airways, but also potentially in the alveolar septa and parenchyma of the lung (e.g. pulmonary embolism, heart failure, altitude sickness), the pharynx and oesophagus, and even the ear, with vagal afferents projecting to the auricular canal from the superior vagal (jugular) ganglia (Arnold's reflex) [34].

Noxious stimuli (e.g. gastric fluid, protons, cigarette smoke, particulates, hyper- or hypotonicity) are detected through receptors and ion channels (e.g. TRPV1, TRPA1, TRPV4, ASIC, P2X3) localised to vagal afferent nerve terminations in the airways mucosa [35]. The vagal afferent nerves regulating cough are polymodal, i.e. responding to a variety of different chemical and mechanical stimuli. Cellular stress releasing ATP appears to be an important stimulus [36]. Afferent neuronal traffic is relayed via vagal axons to the brainstem via at least two different biochemical pathways [37]. Cortical influences modulate the reflex, with females having a greater area of the somatosensory cortex devoted to cough. The system is characterised by marked redundancy, plasticity and adaption. The neurobiology of cough has recently been reviewed comprehensively [38].

Cough may be caused by excessive stimulation of a normal cough reflex such as occurs following inhalation of a foreign body or noxious vapours. However, most patients presenting with a chronic cough have features of cough reflex hypersensitivity, responding to exposure to low levels of thermal, chemical or mechanical stimulation [5]. The cough hypersensitivity syndrome has been adopted as an overarching diagnosis with the different phenotypes dependent on the type and location of the inflammation seen. Both central and peripheral mechanisms have been postulated for cough reflex hypersensitivity [39].

The aetiological mechanisms for cough hypersensitivity remain controversial and are dealt with in greater depth below. In the airways, T2 inflammation occurs in approximately a quarter of patients, although this may be through stimulation of the innate immune system rather than atopy [40]. This gives rise to the phenotypes of cough-variant asthma and eosinophilic bronchitis [41]. Reflux, particularly non-acid gaseous airway reflux, and oesophageal dysmotility are common features [42]. Central mechanisms for cough hypersensitivity have also been postulated, with circumstantial supportive evidence generated using functional magnetic resonance imaging (fMRI) [43]. It is suggested that there is an underlying neuropathic process responsible for cough hypersensitivity [44], a view that is supported by the development of cough in certain forms of hereditary somatosensory neuropathy [45].

\section{Phenotypes of chronic cough}

\section{Asthmatic cough/eosinophilic bronchitis}

Asthma is a clinical diagnosis. There is no agreed single diagnostic test to diagnose or exclude asthma, and because of its heterogeneous presentation opinions differ on how to describe the syndrome in patients with chronic cough. Eosinophilic inflammation may be a useful biomarker of asthmatic cough and may have utility in directing therapeutics. All adults and children with chronic cough may be assessed for eosinophilic inflammation. Sputum eosinophilia is perhaps the most accurate indicator, but is not routinely available, is time-consuming and requires expert interpretation. Exhaled nitric oxide can be used as a surrogate marker of eosinophilic airway inflammation and steroid responsiveness in classic asthma, but its role in asthma and chronic cough is questioned (see later). A meta-analysis of observational studies showed exhaled nitric oxide to have a relatively high specificity of 0.85 in predicting asthma among adult patients with chronic cough [46]; however, there is still no consensus on the cut-off level for the diagnosis. Blood eosinophilia is a simple and readily available measure, but is characterised by diurnal and seasonal variability [47], so multiple assessments should be made [48]. An eosinophil count of $>0.3$ cells $\mu \mathrm{L}^{-1}$ may be taken to indicate eosinophilic airway inflammation $[49,50]$.

Three subgroups of asthmatic cough have been recognised. Classic asthma is characterised by airflow variability and bronchial hyperresponsiveness. Spirometry is thus an obligatory investigation. Cough variant asthma was originally described as occurring in patients with asthma and cough as the sole 
symptoms and where treatment with bronchodilators improved coughing [51]. Opinions vary as to whether this should be sought by performing a bronchial provocation test. Some centres see this as an important part of the workup, whereas others find it adds little to the patient pathway. The third form of asthmatic cough is eosinophilic bronchitis without bronchoconstriction or hyperresponsiveness. The lack of these latter two features has been suggested to indicate that eosinophilic bronchitis is a separate condition: non-asthmatic eosinophilic bronchitis [52]. However, in chronic cough, communication with patients and other healthcare professionals may be enhanced if it is considered as part of an asthmatic spectrum, particularly as all three subgroups can respond to anti-inflammatory asthma therapy. The vital importance of establishing or refuting the diagnosis of asthmatic cough lies in the therapeutics (discussed in questions later) as it may be considered as a treatable trait.

\section{Reflux cough}

The role of reflux, oesophageal dysmotility and aspiration in chronic cough is controversial. Its prevalence has been estimated from 0 to almost $100 \%$. Early studies using the criteria of acid reflux found a low incidence and poor temporal relationship [53]. A systematic review [54] found no significant benefits over placebo of proton-pump inhibitors (PPIs) in patients without acid reflux and only modest benefits even in patients with acid reflux. It was suggested that non-acid reflux, both liquid and gaseous, may be an aetiological factor [55]. However, no technology reliably detects such reflux and the diagnosis relies on the clinical history supported by validated questionnaires such as the Hull Airway Reflux Questionnaire (HARQ) [56] (see www.issc.info for multilingual versions) or reflux symptom index (RSI) [57]. The picture is complicated by the observation that there is a high prevalence of oesophageal dysmotility in patients with chronic cough [42], and thus oesophago-pharyngeal reflux rather than gastro-oesophageal reflux disease may be the problem.

Many of the signs and symptoms associated with chronic cough are explicable by reflux and aspiration. Voice change, nasal symptoms and dysgeusia are common [58]. Frequent "chest infections", bronchitis and even frank bronchiectasis may be the consequence rather than the cause of cough through repeated aspiration. Unsurprisingly, following aspiration of contents from the gastrointestinal tract there is an inflammatory response. This might be neutrophilic or eosinophilic, giving rise to asthmatic cough and mucus hypersecretion [59].

\section{Postnasal drip syndrome/upper airways cough syndrome}

The 2006 American College of Chest Physicians cough management guidelines suggested the term upper airways cough syndrome (UACS) to describe the variety of signs and symptoms previously referred to by other synonyms, including postnasal drip syndrome, rhinitis and rhinosinusitis [60]. However, the revised nomenclature did not resolve ongoing controversy regarding the existence of this syndrome and the mechanism(s) by which it may induce chronic cough.

A first-generation antihistamine and decongestant were recommended as the treatment, in the absence of adequate randomised controlled trial (RCT) evidence. However, the first-generation antihistamines are thought to be antitussive through their action as centrally penetrant anticholinergics [61].

However, UACS could be accepted as an aetiology of chronic cough in some patients by acting as a trigger for cough hypersensitivity, although the mechanism remains obscure. The absence of evidence for localised treatment might suggest that upper airway symptoms merely reflect generalised airway inflammation consequent to asthma or airway reflux.

\section{latrogenic cough}

Chronic cough occurs in $\sim 15 \%$ of patients taking angiotensin-converting enzyme (ACE) inhibitors. ACE inhibitors increase the sensitivity of the cough reflex in most subjects [62] and it is probable that additional factors are required to produce clinical impact. Since the reflex is reset there may be no close temporal relationship to drug administration or withdrawal and the cough [63]. No patient with a cough or who develops one should be given an ACE inhibitor. Angiotensin II antagonists do not affect the cough reflex.

Drugs such as bisphosphonates or calcium channel antagonists may worsen pre-existing reflux disease, causing increased cough. Prostanoid eye drops such as latanoprost may descend the lacrimal duct, irritating the pharynx [64].

\section{Chronic cough in children}

Chronic cough in children differs from that in adults in terms of common aetiologies and management and is increasingly defined as cough that lasts $>4$ weeks. Regardless of setting and age, children with chronic cough should be evaluated carefully using child-specific protocols [65]. 
During childhood, the respiratory tract and nervous system undergo a series of anatomical and physiological maturation processes that influence the cough reflex. Additionally, immunological responses undergo developmental and memorial processes that make infection and congenital abnormalities the predominant causes of cough in children [66]. Thus, tracheomalacia, protracted bacterial bronchitis (PBB) and bronchiectasis occur, in addition to common aetiologies such as asthma and post-infectious cough [67]. PBB is not a new entity, and PBB-like conditions were being reported in the 1980s [68]. An ERS task force has recently advanced a reliable definition of $\mathrm{PBB}$ for day-to-day clinical practice when all three of the following criteria are fulfilled. 1) Presence of continuous chronic ( $>4$ weeks' duration) wet or productive cough; 2) absence of symptoms or signs (i.e. specific cough pointers) suggestive of other causes of wet or productive cough; and 3) cough resolved following a 2-4-week course of an appropriate oral antibiotic [69]. PBB may be a precursor of bronchiectasis [70].

Initial assessment for chronic cough in children includes a detailed history and thorough physical examination to identify possible specific causes due to an underlying disease. A sudden onset of cough in an otherwise healthy preschool child may suggest foreign body aspiration and requires bronchoscopy. A chest radiograph as well as spirometry in children who cooperate is essential. If specific cause for the chronic cough is suspected, further investigations are necessary. In case no specific pointers are detected and chest radiograph and spirometry are normal then the guideline panel considered that another period of observation of up to 4 weeks was indicated. In case of persistence of cough, differentiate between dry and wet cough [71]. Exposure to airborne irritants (e.g. tobacco exposure, combustions, traffic-related exposure, etc.), allergen exposure or post-infectious cough may be a reason for dry chronic cough. In case of wet cough, sputum cultures should be attempted.

Habit/tic cough is another aetiology found particularly in children, manifesting the core clinical features of tics including suppressibility, distractibility, suggestibility, variability and the presence of a premonitory sensation whether the cough is single or one of many tic. The cough formerly named psychosomatic should now be labelled somatic cough disorder and this diagnosis should only be made after an extensive evaluation that includes ruling out tic disorders and uncommon causes of chronic cough [72].

Psychomorbidity is present in all patients with chronic cough with a variety of aetiologies, and tends to decrease following successful treatment [73]. There are limited criteria for the diagnosis of psychogenic (or somatic) cough and features of psychogenic cough reported in the literature are not unique to psychogenic cough [72]. Somatic cough disorder has been commonly used to describe cough without obvious aetiology. However, recent research has revealed neurobiological phenomena are responsible for psychogenic cough [43]. The presence of depression and/or anxiety cannot be used to diagnose psychogenic cough because, as in adults, patients with a persistently troublesome chronic cough can develop these psychological symptoms when their coughs remain untreatable. Nonpharmacological trials of hypnosis or suggestion therapy or combinations of reassurance, counselling or referral to a psychologist and/or psychiatrist have been suggested in management, but such strategies lack an evidence base.

\section{Chronic refractory cough}

A proportion of patients with chronic cough, particularly among adults, have persistent cough despite thorough investigation and treatment according to published practice guidelines. Terms such as idiopathic chronic cough, unexplained chronic cough and chronic refractory cough have been used to describe this clinical condition [74]. Successful trials of drugs with neuromodulatory effects such as opiates, gabapentin and P2X3 antagonists suggest that aberrant neurophysiology is likely to underlie this condition. Here the term chronic refractory cough is used to indicate that the cough is refractory to conventional treatment of cough-associated conditions or traits.

\section{Chronic cough in other diseases}

Most chronic respiratory disease is associated with cough. Physical distortion of the airway such as that which occurs in lung cancer or the bronchorrhea of cystic fibrosis and chronic bronchitis produces cough by mechanical effects. However, cough hypersensitivity through cell damage and inflammation underlies much of the increased cough seen in other pathologies. The different pathological processes in individual conditions contribute to the disease-specific heterogeneous aetiology of cough in other lung disease.

As an example, cough in interstitial lung diseases (ILDs) is common, with a prevalence of $30-90 \%$. Patients with ILD often respond poorly to general antitussive therapy. In an open-label study of idiopathic pulmonary fibrosis (IPF), pirfenidone reduced 24-h objective cough counts and improved cough-related quality of life [75]. Reformulated sodium cromoglicate improved 24 -h objective cough by $31 \%$ in patients with IPF, whereas there was no effect in chronic idiopathic cough [76]. It seems likely that each individual respiratory condition will have its own profile dependent on the tussigenic factors expressed in that disease. 


\section{Chronic cough, tobacco and nicotine}

Smoking is the major remediable cause of chronic cough and is inextricably linked to COPD. Epidemiological studies have demonstrated a relationship between cumulative smoking exposure and chronic cough [77]. Furthermore, smoking history and current cigarette consumption are predictors of objectively measured cough frequency [78]. Therefore, a natural inference would be to ascribe a protussive effect to tobacco smoke and its components. However, research in otherwise healthy smokers and nonsmokers has provided additional insights, some of which contradict the general assumption.

Multiple studies of otherwise healthy smokers have demonstrated suppressed cough reflex sensitivity to inhaled capsaicin $[79,80]$. The development of electronic cigarettes (e-cigs) provided a mechanism of noncombustible delivery of nicotine to the lungs. One tobacco cigarette equivalent induced significant suppression of cough reflex sensitivity [81]. These data are consistent with previous clinical observations of transient increase in cough within the first month after smoking cessation [82]. All patients should quit smoking and they should be warned that there may be a transient increase in coughing. For those unable to quit because of excessive coughing, e-cigs may be a supportive therapy [83]

\section{Assessing cough in the clinic}

\section{Initial assessment}

The history, examination and investigations for patients with chronic cough are performed to exclude treatable traits of the disease for which directed therapy can be offered. The guideline panel placed a higher value on control of any ongoing pathology such as reflux or airway eosinophilia before currently available neuromodulatory treatments are considered. A detailed history and examination should be directed to exclude malignancy, infection, foreign body inhalation or the use of an ACE inhibitor. The impact of cough should be assessed either by recording simple measures such a cough score out of 10 or visual analogue scale (VAS) or by more detailed, validated measures of cough quality of life (LCQ or CQLQ). Validated questionnaires may help to detect features of airway reflux (HARQ and RSI) and airway hypersensitivity [84].

Initial evaluation should include spirometry and a recent chest radiograph (good practice statement).

\section{Chest computed tomography}

Question 1: should chest computed tomography (CT) scan be performed routinely on chronic cough patients with normal chest radiograph and physical examination?

We suggest that clinicians do not routinely perform a chest CT scan in patients with chronic cough who have normal chest radiograph and physical examination (conditional recommendation, very low-quality evidence)

Some prospective and retrospective cohorts identified CT findings in a range of $6.5-58 \%$ of patients with cough and normal chest radiograph; however, the causal relationship was either not specified or considered as unlikely to be related to cough [85-87]. There is a concern about potential cancer risk from CT radiation exposure $[88,89]$. Thus, the potential radiation risk needs to be weighed against possible diagnostic yields, particularly in susceptible populations such as children and females.

\section{Further investigations to identify treatable traits in chronic cough}

Further investigations for asthma, eosinophilic bronchitis, reflux and oesophageal dysmotility and rhinosinusitis should be considered, depending on the clinical history (figure 1).

\section{Asthma and eosinophilic inflammation}

Objective evidence of classic asthmatic cough conventionally requires some evidence of variable airflow obstruction such as peak flow variability, or reversibility to salbutamol of $>12-15 \%$. However, these investigations have a very low negative predictive value, particularly in patients with normal lung function [86]. Further investigation of bronchial hyperresponsiveness using either methacholine or histamine inhalational challenge is advocated by some, although its utility in diagnosis is questioned. Evidence for ongoing airway eosinophilic inflammation can be sought by performing differential cell counts on samples from sputum induction or bronchoalveolar lavage. In such cases, elevated eosinophils $(>3 \%)$ in the airways in the absence of bronchial hyperresponsiveness would suggest eosinophilic bronchitis, which has been reported in up to $13 \%$ of patients attending cough clinics [41]. However, most centres do not have such facilities available, hence a non-invasive alternative is the use of exhaled nitric oxide fractional $\left(F_{\mathrm{eNO}}\right)$ in breath or blood eosinophilia as a surrogate marker to assess airway eosinophilia. The clinical usefulness of $F_{\text {eNO }}$ or blood eosinophils in aiding diagnosis or predicting treatment response in patients with chronic cough has not yet been systematically evaluated [90]. 
History taking and physical examination on presentation

Cough duration

Cough impact and triggers

Family history

Cough score (using VAS or verbal out of 10)

HARQ

Associated symptoms: throat, chest, gastrointestinal

Risk factors: ACE inhibitor, smoking, sleep apnoea

Physical examination: throat, chest, ear
Routine evaluation

Chest radiography

Pulmonary function test

$? F_{\mathrm{eNO}}$

?Blood count for eosinophils

Initial management

Stop risk factors

Initiate corticosteroids (oral or inhaled) or LTRA, particularly when $F_{\mathrm{eNO}}$ or blood eosinophils high

Initiate PPI only when peptic symptoms or evidence of acid reflux are present

Follow-up assessment for cough Cough score (using VAS or 0-10) Associated symptoms

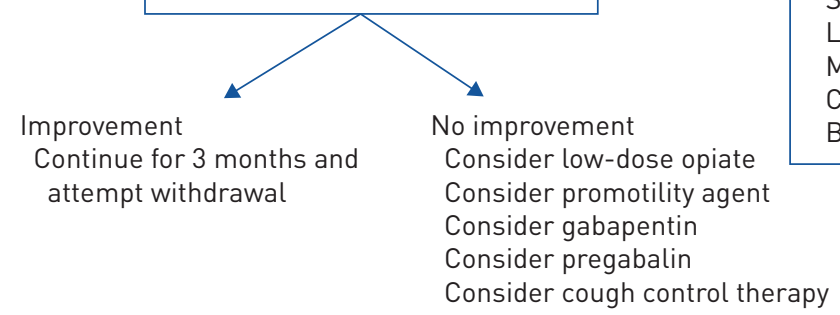

Additional evaluation where indicated High-resolution oesophageal manometry Induced sputum for eosinophils Sputum AAFB Laryngoscope Methacholine challenge

Chest CT

Bronchoscopy

FIGURE 1 Cough assessment in adults. VAS: visual analogue scale; HARQ: Hull Airway Reflux Questionnaire; ACE: angiotensin-converting enzyme; $F_{\mathrm{eNO}}$ : exhaled nitric oxide fraction; LTRA: leukotriene receptor antagonist; PPI: proton-pump inhibitor; AAFB: alcohol and acid-fast bacilli; CT: computed tomography.

Question 2: Should $F_{\text {eNO}} /$ blood eosinophils be used to predict treatment response to corticosteroids/ antileukotrienes in chronic cough?

There is a need for convenient and practical tests for predicting anti-inflammatory treatment responses in patients with chronic cough. However, there is still a lack of quality evidence. Placebo-controlled trials are warranted to assess their utility and also consensus is required on threshold levels in patients with chronic cough.

One RCT [91] in adult non-smoking patients with chronic cough shows that baseline $F_{\text {eNO }}$ levels $(>30 \mathrm{ppb}$ or $<20 \mathrm{ppb}$ ) did not predict response to antileukotrienes. Cough frequency and quality of life were similar

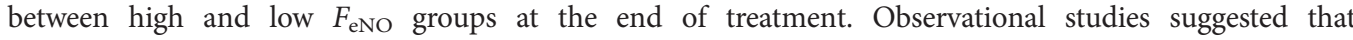
nonresponders to inhaled corticosteroids (ICS) may have significantly lower levels of $F_{\mathrm{eNO}}$ at baseline [92, 93], but the findings were not consistent [94]. Randomised placebo-controlled trials are required to validate the utility or otherwise of $F_{\mathrm{eNO}}$ as a predictor of treatment response in chronic cough patients. Currently, there is no study examining the predictive utility of blood eosinophils in patients with chronic cough.

Given the uncertainty of diagnostic testing, a therapeutic trial may be indicated for asthmatic cough. In adults, oral prednisolone for 1 week may cause a dramatic decrease in cough [95]. ICS may be used when oral administration is contraindicated, and they are preferable in children. However, they may be less effective, since inflammation in cough-variant asthma and eosinophilic bronchitis is located in different parts of the airway from that seen in classic asthma [96], and may be driven by other pathways such as the innate immune system [97]. This also may explain the greater efficacy of systemic leukotriene antagonists such as montelukast in asthmatic cough [98].

\section{Reflux and dysmotility}

In the absence of peptic symptoms 24-h pH monitoring for the investigation of reflux disease is not helpful. However, abnormal oesophageal physiology is very common in patients with chronic cough and may be detected with poor sensitivity by a barium swallow. More accurately, high-resolution oesophageal manometry provides diagnostic information as to the site and mechanism of dysmotility in the majority of patients [42]. 


\section{The upper airways}

In patients who report upper airway symptoms fibre optic laryngoscopy may be performed. The larynx is commonly found to be red and inflamed. However, the test has poor sensitivity and specificity. In select patients, laryngoscopy may be useful in identifying inducible laryngeal obstruction associated with cough, and this may help plan the need for future cough control therapy [99]. Rhinoscopy may be helpful in identifying polyps and clearing mucus from blocked sinuses in patients with recurrent sinus and nasal inflammation, but routine laryngoscopy, rhinoscopy or sinus CT is not advised as nasal findings are not directly associated with cough $[100,101]$.

\section{Chronic cough in children}

Chronic cough in children should be approached using paediatric-specific cough management protocols or algorithms and basing the management on the aetiology of the cough. The most commonly recognised aetiologies for chronic cough in children are post-infectious or natural resolution, asthma and PBB (figure 2).

\section{Treatment of chronic cough}

Even after a thorough clinical assessment, it may be impossible to identify which of the treatable traits is most likely to underlie the patient's chronic cough. Individuals may vary in their response to the different modalities of treatment. The guideline panel considered that it was preferable to undertake sequential therapeutic trials of each agent in turn and if no responses were observed therapy should be stopped. The length of the trial depends on the pharmacology. Response to morphine occurs within 1 week. ICS may take a month to have an effect. If successful, the guideline panel believes that treatment may be continued for several months to allow for resolution of neuronal hypersensitivity. Treatment may then be withdrawn to determine whether remission has occurred. Table 1 provides commentary on the recommendations made.

\section{Anti-asthmatic drugs}

Question 3: should anti-asthmatic drugs (anti-inflammatory or bronchodilator drugs) be used to treat patients with chronic cough?

We suggest a short-term ICS trial (2-4 weeks) in adult patients with chronic cough (conditional recommendation, low-quality evidence).

10 RCTs were identified for chronic cough, but with considerable heterogeneity in patient characteristics, intervention, measured outcomes and treatments responses. Two studies of chronic cough patients (unselected by airway hyperresponsiveness or sputum eosinophilia) found significant benefits from a 2-week high-dose ICS treatment over placebo in reducing cough severity [102] and subjective cough frequency. However, in a study of patients with chronic cough and at least one additional respiratory symptom but with normal lung function, an 8-week medium-dose ICS treatment did not produce a significant improvement in cough severity score over placebo. In two studies of patients with nonasthmatic chronic cough (defined by negative methacholine airway hyperresponsiveness), ICS treatment was not superior to placebo in improving cough outcomes $[103,104]$. In studies of patients with chronic bronchitis or COPD, ICS treatment did not significantly improve subjective cough scores compared to placebo [105-108].

Although the original definition of CVA demonstrated improvement of coughing in a small number of asthmatic subjects with bronchodilator therapy, we do not recommend the use of a lone bronchodilator therapy as maintenance treatment for cough in asthmatic patients. The current Global Initiative for Asthma 2019 guidelines recommend the use of low-dose ICS-formoterol or low-dose ICS. The effectiveness of these treatment regimes in CVA and asthmatic cough still requires further evaluation.

We suggest a short-term ICS trial in children with chronic dry cough (2-4 weeks) (conditional recommendation, low-quality evidence).

Two RCTs were identified. A trial of 50 children aged 1-10 years with persistent nocturnal cough found that there is a modest but significant benefit in objective cough frequency from a 2-week course of high-dose ICS over placebo [109]. Another study of 43 children aged 6-17 years with recurrent cough (two episodes of cough, each lasting 2 weeks in the past 12 months) found no significant effects of ICS in cough outcomes at 4-5 weeks; there was no association between ICS treatment response and airway hyperresponsiveness with hypertonic saline challenge [110].

We suggest a short-term antileukotriene trial (2-4 weeks) in adult patients with chronic cough, particularly in those with asthmatic cough (conditional recommendation, low-quality evidence).

Three RCTs were identified. Two clinical trials [111, 112] of adults with CVA (defined by clinical history, absence of other common diseases and presence of methacholine hyperresponsiveness) found significant 

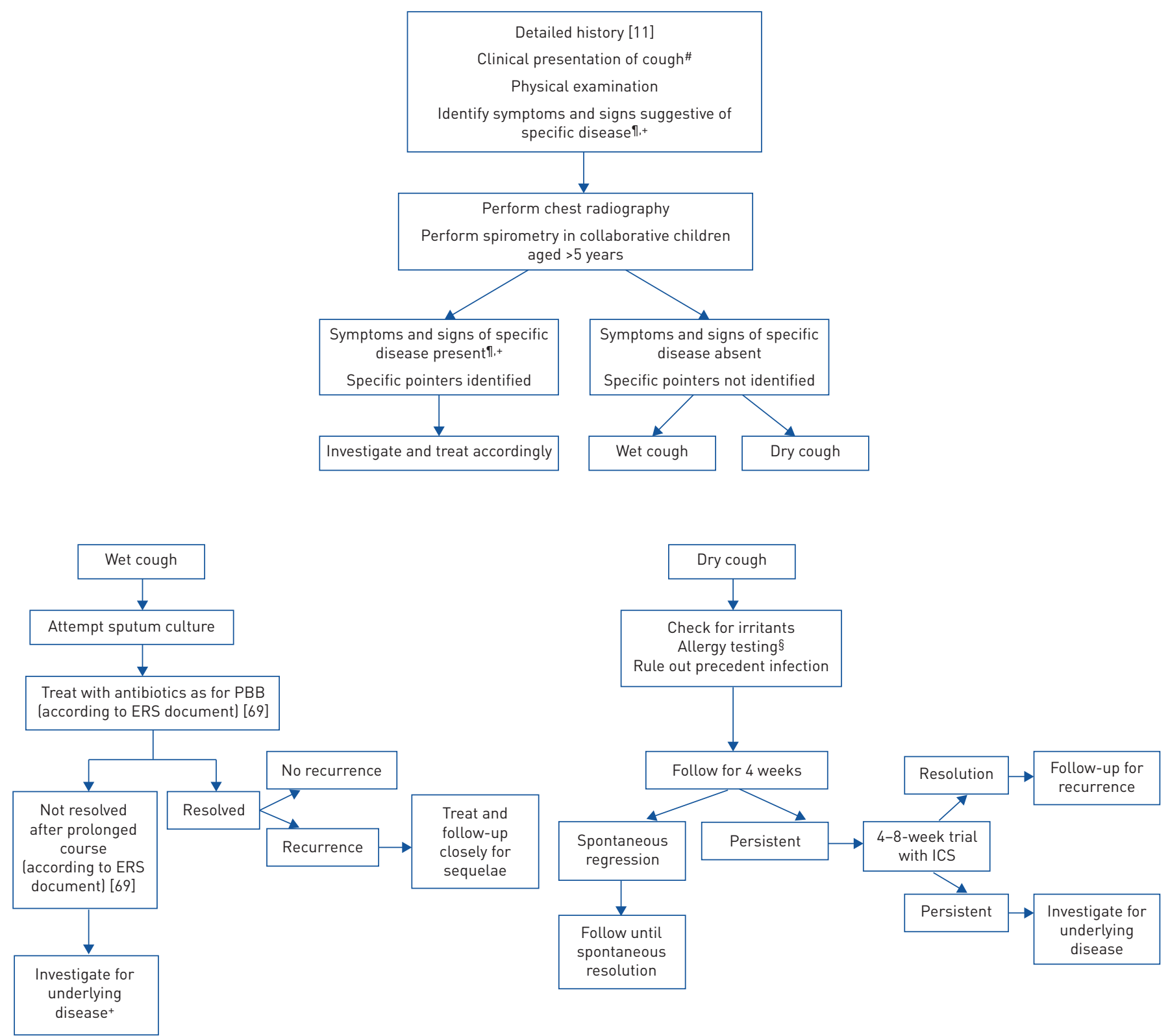

FIGURE 2 Cough assessment flow chart for children. PBB: protracted bacterial bronchitis; ERS: European Respiratory Society; ICS: inhaled corticosteroids. " how and when the cough started, time-course of cough, nature and quality of cough, symptoms associated with cough, triggers of cough, diurnal and nocturnal variations, cough associated with indoor and outdoor irritants; " : chest pain, history suggestive of inhaled foreign body, dyspnoea, exertional dyspnoea, haemoptysis, failure to thrive, feeding difficulties (including choking/vomiting), cardiac or neurodevelopmental abnormalities, recurrent sinopulmonary infections, immunodeficiency, epidemiological risk factors for exposure to tuberculosis, signs of respiratory distress, digital clubbing, chest wall deformity, auscultatory crackles, chest radiographic changes (other than perihilar changes); ${ }^{+}:$cystic fibrosis, primary ciliary dyskinesia, immune deficiency, tuberculosis, aspiration syndromes, tracheobronchomalacia, somatic and tic cough, bronchiectasis, children's interstitial lung disease, upper airway syndrome, asthma, angiotensin-converting enzyme inhibitor-induced cough; §: testing for allergy is not to be routinely performed; it should be undertaken in the presence of features and signs of allergy.

benefits of oral antileukotriene (for 2-4 weeks) over placebo in subjective cough frequency or severity scores. However, a single trial of adults with atopic cough (defined as chronic cough with increased capsaicin cough sensitivity and atopic constitution, but without bronchial hyperresponsiveness) did not find any significant benefits of 2 weeks montelukast over placebo in subjective cough score [113]. Adverse drug events were reported in one study, without any significant events related to the treatment [112]. There are no trials conducted in unselected chronic cough patients.

No RCTs are available for children. Mild, transient neuropsychiatric adverse events are common (>10\%) in children [114]. 
We suggest a short-term trial (2-4 weeks) of ICS and long-acting bronchodilator combination in adults with chronic cough and fixed airflow obstruction (conditional recommendation, moderate-quality evidence).

A single RCT [108] of COPD patients with chronic bronchitis, smoking history and at least one episode of COPD symptom exacerbation in the previous year found that the combination of $50 \mu \mathrm{g}$ salmeterol and $500 \mu \mathrm{g}$ fluticasone twice daily produced a significant improvement in cough severity score compared to placebo (scale 0-4) (mean difference $-0.09,95 \%$ CI $-0.17--0.01$ ), whereas salmeterol or fluticasone monotherapy did not. The treatment was well tolerated, except for an increased incidence of oropharyngeal candidiasis ( $8 \%$ in the combination treatment group versus $2 \%$ in the placebo group).

\section{Anti-acids}

Question 4: Should anti-acid drugs (PPIs and $\mathrm{H}_{2}$-antagonists) be used to treat patients with chronic cough?

We suggest that clinicians do not routinely prescribe anti-acid drugs in adult patients with chronic cough (conditional recommendation, low-quality evidence).

Anti-acid drugs are unlikely to be useful in improving cough outcomes, unless patients have peptic symptoms or evidence of acid reflux. Systematic reviews have found no significant benefits from PPI over placebo in adult patients without acid reflux and possible modest effect in those with acid reflux [54]. FARUQI et al. [115] found no significant benefits of esomeprazole $20 \mathrm{mg}$ twice daily therapy over placebo in subjective cough frequency, cough severity or cough-specific quality-of-life scores at 8 weeks. There was a trend towards greater improvement in the PPI treatment arm in patients with dyspepsia. In a study of chronic cough patients with rare or no heartburn, there were no benefits from a long-term high-dose PPI therapy (esomeprazole $40 \mathrm{mg}$ twice daily for 12 weeks) in cough-specific quality of life or cough scores [116]. While PPI is frequently considered safe, observational studies reported potential risks of iron deficiency, vitamin B12 deficiency, hypomagnesemia, Clostridium difficile-associated diarrhoea, osteoporosis-related bone fracture, dementia or pneumonia [117, 118]. However, direct evidence about the safety issues is lacking in the chronic cough population. There is not enough evidence to draw a specific recommendation for PPI use in children.

\section{Drugs with promotility activity}

Question 5: should drugs with promotility activity be used to treat patients with chronic cough?

There is currently insufficient evidence to recommend the routine use of macrolide therapy in chronic cough. A 1-month trial of macrolides can be considered in the cough of chronic bronchitis refractory to other therapy, taking into account local guidelines on antimicrobial stewardship (conditional recommendation, low-quality evidence).

No RCTs have been undertaken with promotility agents, such as baclofen, metoclopramide or domperidone, in patients with chronic cough. There are three RCTs with macrolides with promotility activity in adult patients with chronic cough. One study of patients with COPD Global Initiative for Chronic Obstructive Lung Disease stage $\geqslant 2$ and chronic productive cough demonstrated a significant benefit of a 12-week low-dose azithromycin ( $250 \mathrm{mg}$ three times a week) over placebo for improving cough-specific quality of life (LCQ; mean difference 1.3, 95\% CI 0.3-2.3; p=0.01) [119]. Adverse events were not significantly different. In two other trials of patients with unexplained cough or treatment-resistant cough, low-dose macrolide treatments (erythromycin $250 \mathrm{mg}$ daily for 12 weeks or azithromycin $250 \mathrm{mg}$ three times a week for 8 weeks) did not provide significant benefits over placebo for objective cough frequency, cough severity or cough-specific quality of life [120, 121].

\section{Neuromodulators}

Question 6: which cough neuromodulatory agents (pregabalin, gabapentin, tricyclics and opiates) should be used to treat patients with chronic cough?

We recommend a trial of low-dose slow-release morphine (5-10 mg twice daily) in adult patients with chronic refractory cough (strong recommendation, moderate-quality evidence).

A single RCT of low-dose morphine (5-10 mg twice daily) in adults with chronic refractory cough found significant benefits over placebo in reducing cough severity (self-reported scale 0-9 points) (mean difference -1.96 points, $95 \%$ CI $-1.09--2.11$ points) and improving cough-specific quality of life (LCQ) (mean difference 2 points, 95\% CI 0.93-3.07 points) [27]. Common adverse effects in this clinical trial were constipation and drowsiness in patients receiving morphine. 
We suggest a trial of gabapentin or pregabalin in adults with chronic refractory cough (conditional recommendation, low-quality evidence).

A single RCT of gabapentin therapy (maximum tolerable daily dose of $1800 \mathrm{mg}$ ) in adults with chronic refractory cough found significant benefits over placebo in improving LCQ (mean difference 1.8 points, 95\% CI 0.56-3.04 points) and reducing cough frequency (although only of a single hour of observation) (mean difference $-27.31 \%, 95 \%$ CI $-2.87--51.75 \%$ ) and severity (VAS 0-100 points) (mean difference -12.33 points, $95 \%$ CI $-1.23--23.23$ ) [122]. There is one RCT of pregabalin therapy (300 mg daily) in adult patients with chronic refractory cough alongside speech pathology therapy [123]. Pregabalin plus speech pathology therapy significantly improved cough-specific quality of life (LCQ) (mean difference 3.5 points, 95\% CI 1.11-5.89; minimal important difference 1.3 points) and cough severity (VAS 0100 points) (mean difference -25.1 points, 95\% CI $-10.6--39.6$ points) over placebo plus speech pathology therapy. There was no significant reduction in cough frequency. There is no comparison between pregabalin and placebo alone. An explanation for a lack of effect on cough frequency is that centrally acting therapies may alter the perception of cough, rather than having truly antitussive effects. In addition, they could affect the intensity of coughing without reducing the frequency. Dizziness, fatigue, cognitive changes, nausea or blurred vision are common side-effects of gabapentin and pregabalin. A systematic review revealed that the risk of withdrawal due to adverse events is 2.3 times higher than placebo [124].

Use of agents acting directly on cough hypersensitivity rather than the treatable traits causing hypersensitivity is a promising strategy for future developments. Current agents have been shown to be effective in adults, but the side-effect profile is significant and may be mitigated by the use of lower doses than those used to treat pain.

Cough neuromodulators, such as opioids, gabapentin or pregabalin, are not used in children, due to reported adverse events, possible toxicity and lack of clinical trials [125].

\section{Nonpharmacological cough control therapy}

Question 7: should nonpharmacological therapy (cough control therapy) be used to treat patients with chronic cough?

We suggest a trial of cough control therapy in adult patients with chronic cough (conditional recommendation, moderate quality evidence).

Two RCTs of physiotherapy/speech and language therapy (cough control therapy) in adult patients with chronic refractory cough have been reported. VerTigan et al. [126] demonstrated that the 2-month intervention significantly reduced subjective cough score compared to placebo treatment (self-reported scale $2-10$ points) (mean difference 2.8 points, $95 \%$ CI $1.3-4.0$ ). In a multicentre study by CHAMBERLAIN Mitchell et al. [127], the weekly intervention for 4 weeks showed benefits over placebo for cough-specific quality of life (LCQ; 1.53 points, 95\% CI $0.21-2.85$ points) and objective cough frequency (fold change) $(0.59,95 \%$ CI $0.36-0.95)$, but not for VAS severity or other quality-of-life outcomes. The improvements in the intervention group were sustained up to 3 months, but not beyond. No adverse effects were found. There are no RCTs in children. This is a complex intervention that requires further study to determine which components are of value. Experienced practitioners should undertake cough-directed physiotherapy and speech and language therapy interventions.

\section{Antibiotics for chronic wet cough in children}

Question 8: in children with chronic wet cough with normal chest radiograph, normal spirometry and no warning signs, should a trial of antibiotics be used?

A trial of antibiotics is suggested in children with chronic wet cough with normal chest radiographs, normal spirometry and no warning signs (conditional recommendation, low-quality evidence).

A single RCT of antibiotics in young children (mean age 1.9 years; interquartile range 0.9-5.1 years) with chronic wet cough ( $>3$ weeks) [128]. A 2-week regimen of twice-daily oral amoxicillin clavulanate treatment $\left(22.5 \mathrm{mg} \cdot \mathrm{kg}^{-1}\right.$ per dose) was compared. Cough resolution rates (defined as $>75 \%$ reduction) were significantly higher in children who received amoxicillin clavulanate compared with those who received placebo ( $48 \%$ versus $16 \%$; $=0.015$ ). Side-effects were not significantly different between two groups; however, mild diarrhoea was found to be slightly greater in the in the amoxicillin clavulanate group than in the placebo group (five out of 25 versus two out of 25) [128]. 


\section{Future directions and new drugs}

As the population ages, the worldwide prevalence of chronic cough increases. This is partially due to an increasing awareness of the problem, changing diagnostic labels, air pollution and increased efforts in educating health professionals. Changes in society, such as the rise in obesity, will also predispose to a greater incidence of causal factors related to chronic cough. Our understanding of the pathophysiological basis of chronic cough has dramatically advanced over the past decade with the realisation that neuronal hypersensitivity underlies the syndrome. Desensitisation through the use of agonists such as capsaicin has recently shown promise as a therapeutic strategy [129]. However, we are still grossly ignorant of the complex interplay in the peripheral and central nervous system. fMRI has given us insights into the central pathways of cough and will continue to do so in the future. However, it is the pharmacology of the peripheral afferent vagus which has given us the most hopeful future therapeutic developments.

Much effort was devoted to the development of blockers of the nociceptors, mainly transient receptor potential receptors, which are responsible for the irritant sensation leading to the tickle that precedes cough. While effective in animal models, these agents have failed in the clinic $[130,131]$. The substance $\mathrm{P}$ antagonist orvepitant has shown modest efficacy in phase 2 studies. However, one class of drugs has produced a dramatic improvement in chronic cough in phase 2 studies [132]. ATP is released during cell damage and acts on afferent sensory nerves through P2X3 purinergic receptors. The first antagonist, gefapixant, has been studied in several hundred patients with chronic cough with resolution in the majority. Other compounds in this class are in development and we may have the first effective drugs for chronic cough in $>40$ years.

\section{Research gaps and recommendations for future studies}

Because chronic cough has only recently been recognised as a separate entity, a major challenge is the promulgation of the concept of cough hypersensitivity in adults and conditions such as protracted bacterial bronchitis in children. While the aim of these guidelines is to further awareness we recognise the scale of the task and recommend that the ERS should advocate chronic cough as a classification in the World Health Organization International Classification of Diseases.

Very little is known of the natural history of chronic cough. We recommend observational cohort studies to identify the true prevalence of chronic cough in the population; the demographic characteristics of this patient population; the natural history of chronic cough over time; the clinical and psychosocial impact of chronic cough on patients; and the economic burden of chronic cough, both to the individual and society.

The assessment of chronic cough in both the clinical and research settings needs further development. Current instruments to assess quality of life need refinement to be useful in routine clinical practice. Patient reported outcomes need to be developed and validated. There is an urgent need for fully automated cough recording technology that continuously monitors patients in real time. Such devices may help confirm the diagnosis in the clinic, allow for objective assessment of clinical response, and ensure the entry of the correct population into clinical studies. In addition, the current clinical approach is largely based on sequential therapeutic trials; thus, practical biomarkers need to be developed to target treatable traits and guide treatment decisions in the clinic.

There are very few studies of cough in other diseases and currently patients with the syndrome of chronic cough are frequently mislabelled as suffering from other conditions. Studies of the overlap between respiratory disease and chronic cough are urgently needed, particularly in view of the differences in pathophysiology and treatable traits.

Conflict of interest: A.H. Morice reports grants, personal fees, non-financial support and other (advisory board participation) from Merck Sharp \& Dohme Corp., Bayer AG Research \& Development, Bayer US, Sanofi and Phillips Respironics, personal fees, non-financial support and other (advisory board participation) from Bellus Health, personal fees and non-financial support from AstraZeneca, Chiesi Ltd and Boehringer Ingelheim, grants, personal fees and non-financial support from GlaxoSmithKline and Respivant Sciences, Inc., grants, personal fees and other (advisory board participation) from NeRRe Therapeutics, grants from Menlo Therapeutics, during the conduct of the study. E. Millqvist filed an international patent application (PCT application) for the use of capsaicin as a cough-reducing product on January 3, 2014. There is a pending patent application in the USA, Canada and the EU. In Australia a patent was issued on August 17 2017. However, this treatment method is not described, recommended or emphasised in any way in the guidelines. K. Bieksiene has nothing to disclose. S.S. Birring reports grants from Merck, personal fees for advisory board work from Merck, Bayer, GSK, Menlo and Sanofi, travel expenses reimbursement from Boehringer Ingleheim, outside the submitted work. P. Dicpinigaitis has nothing to disclose. C. Domingo Ribas reports personal fees for lectures and advisory board participation from MSD, AstraZeneca, ALK and Sanofi-Aventis, personal fees for lectures, advisory board participation and non-financial support (study collaboration) from Novartis and Teva, personal fees for meeting attendance from Allergy Therapeutics, Immunotek, Esteve and Menarini, personal fees from Chiesi, personal fees for lectures from Ferrer, non-financial support (study collaboration) from GSK, outside the submitted work. M. Hilton Boon reports grants from Medical Research Council (UK) (MC_UU_12017/15), and from Scottish Government Chief Scientist Office (SPHSU15), during the conduct of the study. A. Kantar is advisor for study design of 
an unlicensed product (Merck Sharp \& Dohme, USA); advisor for study design of an over-the-counter product (Sanofi, Germany) and (Infirst, UK). No financial or intellectual conflicts of interest regarding the content of this manuscript. K. Lai reports grants and personal fees from AstraZeneca, GlaxoSmithKline, Merck, Daiyichi Sankyo and Novartis, outside the submitted work. L. McGarvey reports personal fees from Merck \& Co., Inc. and AstraZeneca, grants, personal fees and non-financial support from Chiesi, personal fees and non-financial support from Boehringer Ingelheim, grants and non-financial support from GlaxoSmithKline, grants and personal fees from Almirall, grants from NC3R, during the conduct of the study; grants from European Union Interreg VA Health \& Life Science Programme, outside the submitted work. D. Rigau acts as methodologist for the ERS. I. Satia is currently supported by ERS Marie Curie Respire 3 Global Fellowship programme (713406), and reports grants from BMA James Trust Award, grants from North West Lung Centre Charity Grant, personal fees for lectures from GSK and AstraZeneca, travel Awards for attending conferences from GSK and Chiesi, outside the submitted work. J. Smith reports grants and personal fees for consultancy and advisory board work from GlaxoSmithKline, grants and personal fees for consultancy from NeRRe Pharmaceuticals, Menlo, Bayer, Axalbion and Merck, personal fees for consultancy from Boehringer Ingelheim, Genentech, Neomed, Chiesi and Bellus, non-financial support (provision of cough monitoring equipment) from Vitalograph, grants and personal fees from Afferent, personal fees for consultancy and non-financial support (scientific collaboration support in kind) from AstraZeneca, outside the submitted work; and has a patented method for generating output data licensed. W-J. Song has nothing to disclose. T. Tonia acts as ERS methodologist. J.W.K. van den Berg reports personal fees for advisory board work from MSD, grants from Bayer, outside the submitted work. M.J.G. van Manen has nothing to disclose. A. Zacharasiewicz reports payment for consultancy work for Vertex, Novartis, Abbvie and Loewenstein, travel sponsorship from Mylan, Chiesi and Teva, support for research from Abbvie.

Support statement: This work was funded by the European Respiratory Society. Funding information for this article has been deposited with the Crossref Funder Registry.

\section{References}

1 Song WJ, Chang YS, Faruqi S, et al. The global epidemiology of chronic cough in adults: a systematic review and meta-analysis. Eur Respir J 2015; 45: 1479-1481.

2 Chamberlain SA, Garrod R, Douiri A, et al. The impact of chronic cough: a cross-sectional European survey. Lung 2015; 193: 401-408.

3 Morice $\mathrm{AH}$, Jakes $\mathrm{AD}$, Faruqi S, et al. A worldwide survey of chronic cough: a manifestation of enhanced somatosensory response. Eur Respir J 2014; 44: 1149-1155.

$4 \quad$ Millqvist E. The airway sensory hyperreactivity syndrome. Pulm Pharmacol Ther 2011; 24: 263-266.

5 Morice AH, Millqvist E, Belvisi MG, et al. Expert opinion on the cough hypersensitivity syndrome in respiratory medicine. Eur Respir J 2014; 44: 1132-1148.

6 Chang AB. Pediatric cough: children are not miniature adults. Lung 2010; 188: Suppl. 1, S33-S40.

7 Miravitlles M, Tonia T, Rigau D, et al. New era for European Respiratory Society clinical practice guidelines: joining efficiency and high methodological standards. Eur Respir J 2018; 51: 1800221.

8 Song WJ, Chang YS, Faruqi S, et al. Defining chronic cough: a systematic review of the epidemiological literature. Allergy Asthma Immunol Res 2016; 8: 146-155.

9 Morice AH, Fontana GA, Belvisi MG, et al. ERS guidelines on the assessment of cough. Eur Respir J 2007; 29: $1256-1276$.

10 Chang AB, Glomb WB. Guidelines for evaluating chronic cough in pediatrics: ACCP evidence-based clinical practice guidelines. Chest 2006; 129: Suppl. 1, 260S-283S.

11 Shields MD, Bush A, Everard ML, et al. BTS guidelines: recommendations for the assessment and management of cough in children. Thorax 2008; 63: Suppl. 3, iiil-iii15.

12 Morice AH. Epidemiology of cough. Pulm Pharmacol Ther 2002; 15: 253-259.

13 Ford AC, Forman D, Moayyedi P, et al. Cough in the community: a cross sectional survey and the relationship to gastrointestinal symptoms. Thorax 2006; 61: 975-979.

14 Colak Y, Nordestgaard BG, Laursen LC, et al. Risk factors for chronic cough among 14,669 individuals from the general population. Chest 2017; 152: 563-573.

15 Kang MG, Song WJ, Kim HJ, et al. Point prevalence and epidemiological characteristics of chronic cough in the general adult population: the Korean National Health and Nutrition Examination Survey 2010-2012. Medicine 2017; 96: e6486.

16 Lätti AM, Pekkanen J, Koskela HO. Defining the risk factors for acute, subacute and chronic cough: a cross-sectional study in a Finnish adult employee population. BMJ Open 2018; 8: e022950.

17 Kogan MD, Pappas G, Yu SM, et al. Over-the-counter medication use among US preschool-age children. JAMA 1994; 272: 1025-1030.

18 Singh D, Arora V, Sobti PC. Chronic/recurrent cough in rural children in Ludhiana, Punjab. Indian Pediatr 2002; 39: 23-29.

19 Leonardi GS, Houthuijs D, Nikiforov B, et al. Respiratory symptoms, bronchitis and asthma in children of Central and Eastern Europe. Eur Respir J 2002; 20: 890-898.

20 Pan G, Zhang S, Feng Y, et al. Air pollution and children's respiratory symptoms in six cities of Northern China. RespirMed 2010; 104: 1903-1911.

21 Dales RE, White J, Bhumgara C, et al. Parental reporting of childrens' coughing is biased. Eur J Epidemiol 1997; 13: 541-545.

22 French CL, Irwin RS, Curley FJ, et al. Impact of chronic cough on quality of life. Arch Intern Med 1998; 158: $1657-1661$.

23 Raj AA, Birring SS. Clinical assessment of chronic cough severity. Pulm Pharmacol Ther 2007; 20: 334-337.

24 French CL, Crawford SL, Bova C, et al. Change in psychological, physiological, and situational factors in adults after treatment of chronic cough. Chest 2017; 152: 547-562.

25 French CT, Irwin RS, Fletcher KE, et al. Evaluation of cough-specific quality-of-life questionnaire. Chest 2002; 121: 1123-1131.

26 Birring SS, Prudon B, Carr AJ, et al. Development of a symptom specific health status measure for patients with chronic cough: Leicester Cough Questionnaire (LCQ). Thorax 2003; 58: 339-343. 
Morice AH, Menon MS, Mulrennan SA, et al. Opiate therapy in chronic cough. Am J Respir Crit Care Med 2007 175: 312-315.

Marchant JM, Newcombe PA, Juniper EF, et al. What is the burden of chronic cough for families? Chest 2008; 134: 303-309.

Kantar A, Bernardini R, Paravati F, et al. Chronic cough in preschool children. Early Hum Dev 2013; 89: Suppl. 3, S19-S24.

Luyt DK, Burton PR, Simpson H. Epidemiological study of wheeze, doctor diagnosed asthma, and cough in preschool children in Leicestershire. BMJ 1993; 306: 1386-1390.

Chang AB, Landau LI, Van Asperen PP, et al. Cough in children: definitions and clinical evaluation. Med J Aust 2006; 184: 398-403.

Demoulin-Alexikova S, Plevkova J, Mazurova L, et al. Impact of air pollution on age and gender related increase in cough reflex sensitivity of healthy children in Slovakia. Front Physiol 2016; 7: 54.

Ebihara S, Ebihara T, Kohzuki M. Effect of aging on cough and swallowing reflexes: implications for preventing aspiration pneumonia. Lung 2012; 190: 29-33.

2011: 24: 295-299.

Belvisi MG, Birrell MA, Khalid S, et al. Neurophenotypes in airway diseases: insights from translational cough studies. Am J Respir Crit Care Med 2016; 193: 1364-1372.

Bonvini SJ, Birrell MA, Grace MS, et al. Transient receptor potential cation channel, subfamily V, member 4 and airway sensory afferent activation: role of adenosine triphosphate. J Allergy Clin Immunol 2016; 138: 249-261.

Morice AH, Kitt MM, Ford AP, et al. The effect of gefapixant, a P2X3 antagonist, on cough reflex sensitivity: a randomised placebo-controlled study. Eur Respir J 2019; 54: 1900439.

Mazzone SB, Farrell MJ. Heterogeneity of cough neurobiology: clinical implications. Pulm Pharmacol Ther 2019; 55: 62-66.

Mazzone SB, Chung KF, McGarvey L. The heterogeneity of chronic cough: a case for endotypes of cough hypersensitivity. Lancet Respir Med 2018; 6: 636-646.

Lund S, Walford HH, Doherty TA. Type 2 innate lymphoid cells in allergic disease. Curr Immunol Rev 2013; 9: 214-221.

Brightling CE, Ward R, Goh KL, et al. Eosinophilic bronchitis is an important cause of chronic cough. Am Respir Crit Care Med 1999; 160: 406-410.

Burke JM, Jackson W, Morice AH. The role of high resolution oesophageal manometry in occult respiratory symptoms. Respir Med 2018; 138: 47-49.

Ando A, Smallwood D, McMahon M, et al. Neural correlates of cough hypersensitivity in humans: evidence for central sensitisation and dysfunctional inhibitory control. Thorax 2016; 71: 323-329.

Chung KF, McGarvey LP, Mazzone SB. Chronic cough as a neuropathic disorder. Lancet Respir Med 2013; 1 : $412-422$.

Spring PJ, Kok C, Nicholson GA, et al. Autosomal dominant hereditary sensory neuropathy with chronic cough and gastro-oesophageal reflux: clinical features in two families linked to chromosome 3p22-p24. Brain 2005; 128: 2797-2810.

Song WJ, Kim HJ, Shim JS, et al. Diagnostic accuracy of fractional exhaled nitric oxide measurement in predicting cough-variant asthma and eosinophilic bronchitis in adults with chronic cough: a systematic review and meta-analysis. J Allergy Clin Immunol 2017; 140: 701-709.

Mathur SK, Fichtinger PS, Evans MD, et al. Variability of blood eosinophil count as an asthma biomarker. Ann Allergy Asthma Immunol 2016; 117: 551-553.

Hamad GA, Cheung W, Crooks MG, et al. Eosinophils in COPD: how many swallows make a summer? Eur Respir J 2018; 51: 1702177.

Wagener AH, de Nijs SB, Lutter R, et al. External validation of blood eosinophils, $F_{\mathrm{ENO}}$ and serum periostin as surrogates for sputum eosinophils in asthma. Thorax 2015; 70: 115-120.

Magnussen H, Disse B, Rodriguez-Roisin R, et al. Withdrawal of inhaled glucocorticoids and exacerbations of COPD. N Engl J Med 2014; 371: 1285-1294.

Corrao WM, Braman SS, Irwin RS. Chronic cough as the sole presenting manifestation of bronchial asthma. N Engl J Med 1979; 300: 633-637.

Gibson PG, Dolovich J, Denburg J, et al. Chronic cough: eosinophilic bronchitis without asthma. Lancet 1989; 1: 1346-1348. pathogenetic aspects. Chest 1993; 104: 1511-1517.

Kahrilas PJ, Howden CW, Hughes N, et al. Response of chronic cough to acid-suppressive therapy in patients with gastroesophageal reflux disease. Chest 2013; 143: 605-612. associated with cough. J Clin Gastroenterol 2009; 43: 414-419. 89: 73-79.

Belafsky PC, Postma GN, Koufman JA. Validity and reliability of the reflux symptom index (RSI). J Voice 2002; 16: $274-277$.

Everett CF, Morice AH. Clinical history in gastroesophageal cough. Respir Med 2007; 101: 345-348. cough. Respirology 2011; 16: 994-999.

Irwin RS, Baumann MH, Bolser DC, et al. Diagnosis and management of cough executive summary: ACCP evidence-based clinical practice guidelines. Chest 2006; 129: Suppl. 1, 1S-23S.

Dicpinigaitis PV, Morice AH, Birring SS, et al. Antitussive drugs - past, present, and future. Pharmacol Rev 2014; 66: 468-512.

Morice AH, Lowry R, Brown MJ, et al. Angiotensin converting enzyme and the cough reflex. Lancet 1987; 2: $1116-1118$. 

423-429.

64 Fahim A, Morice AH. Heightened cough sensitivity secondary to latanoprost. Chest 2009; 136: 1406-1407.

65 Chang AB, Oppenheimer JJ, Weinberger MM, et al. Use of management pathways or algorithms in children with chronic cough: CHEST guideline and expert panel report. Chest 2017; 151: 875-883.

66 Kantar A. Update on pediatric cough. Lung 2016; 194: 9-14.

67 Chang AB, Robertson CF, van Asperen PP, et al. A cough algorithm for chronic cough in children: a multicenter, randomized controlled study. Pediatrics 2013; 131: e1576-e1583.

68 Taussig LM, Smith SM, Blumenfeld R. Chronic bronchitis in childhood: what is it? Pediatrics 1981; 67: 1-5.

69 Kantar A, Chang AB, Shields MD, et al. ERS statement on protracted bacterial bronchitis in children. Eur Respir J 2017; 50: 1602193.

70 Wurzel DF, Marchant JM, Yerkovich ST, et al. Protracted bacterial bronchitis in children: natural history and risk factors for bronchiectasis. Chest 2016; 150: 1101-1108.

71 Chang AB, Oppenheimer JJ, Weinberger M, et al. Children with chronic wet or productive cough - treatment and investigations: a systematic review. Chest 2016; 149: 120-142.

72 Haydour Q, Alahdab F, Farah M, et al. Management and diagnosis of psychogenic cough, habit cough, and tic cough: a systematic review. Chest 2014; 146: 355-372.

73 Vertigan AE. Somatic cough syndrome or psychogenic cough - what is the difference? J Thorac Dis 2017; 9: 831-838.

74 McGarvey L, Gibson PG. What is chronic cough? Terminology. J Allergy Clin Immunol Pract 2019; 7: 1711-1714.

75 van Manen MJG, Birring SS, Vancheri C, et al. Effect of pirfenidone on cough in patients with idiopathic pulmonary fibrosis. Eur Respir J 2017; 50: 1701157.

76 Birring SS, Wijsenbeek MS, Agrawal S, et al. A novel formulation of inhaled sodium cromoglicate (PA101) in idiopathic pulmonary fibrosis and chronic cough: a randomised, double-blind, proof-of-concept, phase 2 trial. Lancet Respir Med 2017; 5: 806-815.

77 Freund KM, Belanger AJ, D'Agostino RB, et al. The health risks of smoking. The Framingham Study: 34 years of follow-up. Ann Epidemiol 1993; 3: 417-424.

78 Sumner H, Woodcock A, Kolsum U, et al. Predictors of objective cough frequency in chronic obstructive pulmonary disease. Am J Respir Crit Care Med 2013; 187: 943-949.

79 Millqvist E, Bende M. Capsaicin cough sensitivity is decreased in smokers. Respir Med 2001; 95: 19-21.

80 Dicpinigaitis PV. Cough reflex sensitivity in cigarette smokers. Chest 2003; 123: 685-688.

81 Dicpinigaitis PV, Lee Chang A, Dicpinigaitis AJ, et al. Effect of e-cigarette use on cough reflex sensitivity. Chest 2016; 149: 161-165.

82 Cummings KM, Giovino G, Jaén CR, et al. Reports of smoking withdrawal symptoms over a 21 day period of abstinence. Addict Behav 1985; 10: 373-381.

83 Hajek P, Phillips-Waller A, Przulj D, et al. A randomized trial of e-cigarettes versus nicotine-replacement therapy. N Engl J Med 2019; 380: 629-637.

84 Nordin S, Palmquist E, Bende M, et al. Normative data for the chemical sensitivity scale for sensory hyperreactivity: the Västerbotten Environmental Health Study. Int Arch Occup Environ Health 2013; 86: 749-753.

85 Kastelik JA, Aziz I, Ojoo JC, et al. Investigation and management of chronic cough using a probability-based algorithm. Eur Respir J 2005; 25: 235-243.

86 McGarvey LP, Heaney LG, Lawson JT, et al. Evaluation and outcome of patients with chronic non-productive cough using a comprehensive diagnostic protocol. Thorax 1998; 53: 738-743.

87 French CT, Diekemper RL, Irwin RS, et al. Assessment of intervention fidelity and recommendations for researchers conducting studies on the diagnosis and treatment of chronic cough in the adult: CHEST guideline and expert panel report. Chest 2015; 148: 32-54.

88 Berrington de González A, Mahesh M, Kim K-P, et al. Projected cancer risks from computed tomographic scans performed in the United States in 2007. Arch Intern Med 2009; 169: 2071-2077.

89 Brenner DJ, Hall EJ. Computed tomography - an increasing source of radiation exposure. $N$ Engl J Med 2007; 357: 2277-2284.

90 Sadeghi MH, Wright CE, Hart S, et al. Phenotyping patients with chronic cough: evaluating the ability to predict the response to anti-inflammatory therapy. Ann Allergy Asthma Immunol 2018; 120: 285-291.

91 Sadeghi MH, Wright CE, Hart S, et al. Does $F_{\text {eNO }}$ predict clinical characteristics in chronic cough? Lung 2018; 196: 59-64.

92 Watanabe K, Shinkai M, Shinoda M, et al. Measurement of eNO with portable analyser might improve the management of persistent cough at primary care practice in Japan. Clin Respir J 2016; 10: 380-388.

93 Hahn PY, Morgenthaler TY, Lim KG. Use of exhaled nitric oxide in predicting response to inhaled corticosteroids for chronic cough. Mayo Clin Proc 2007; 82: 1350-1355.

94 Prieto L, Ferrer A, Ponce S, et al. Exhaled nitric oxide measurement is not useful for predicting the response to inhaled corticosteroids in subjects with chronic cough. Chest 2009; 136: 816-822.

95 Doan T, Patterson R, Greenberger PA. Cough variant asthma: usefulness of a diagnostic-therapeutic trial with prednisone. Ann Allergy 1992; 69: 505-509.

96 Brightling CE, Bradding P, Symon FA, et al. Mast-cell infiltration of airway smooth muscle in asthma. $N$ Engl $J$ Med 2002; 346: 1699-1705.

97 Jia Y, Fang X, Zhu X, et al. IL- $13^{+}$type 2 innate lymphoid cells correlate with asthma control status and treatment response. Am J Respir Cell Mol Biol 2016; 55: 675-683.

98 Takemura M, Niimi A, Matsumoto H, et al. Clinical, physiological and anti-inflammatory effect of montelukast in patients with cough variant asthma. Respiration 2012; 83: 308-315.

99 Vertigan AE, Kapela SM, Kearney EK, et al. Laryngeal dysfunction in cough hypersensitivity syndrome: a cross-sectional observational study. J Allergy Clin Immunol Pract 2018; 6: 2087-2095.

100 O'Hara J, Jones NS. "Post-nasal drip syndrome": most patients with purulent nasal secretions do not complain of chronic cough. Rhinology 2006; 44: 270-273. 
101 Pratter MR, Bartter T, Lotano R. The role of sinus imaging in the treatment of chronic cough in adults. Chest 1999; 116: 1287-1291.

102 Chaudhuri R, McMahon AD, Thomson LJ, et al. Effect of inhaled corticosteroids on symptom severity and sputum mediator levels in chronic persistent cough. J Allergy Clin Immunol 2004; 113: 1063-1070.

103 Boulet LP, Milot J, Boutet M, et al. Airway inflammation in nonasthmatic subjects with chronic cough. Am J Respir Crit Care Med 1994; 149: 482-489.

104 Pizzichini MM, Pizzichini E, Parameswaran K, et al. Nonasthmatic chronic cough: no effect of treatment with an inhaled corticosteroid in patients without sputum eosinophilia. Can Respir J 1999; 6: 323-330.

105 Engel T, Heinig JH, Madsen O, et al. A trial of inhaled budesonide on airway responsiveness in smokers with chronic bronchitis. Eur Respir J 1989; 2: 935-939.

106 Wesseling GJ, Quaedvlieg M, Wouters EF. Inhaled budesonide in chronic bronchitis. Effects on respiratory impedance. Eur Respir J 1991; 4: 1101-1105.

107 Paggiaro PL, Dahle R, Bakran I, et al. Multicentre randomised placebo-controlled trial of inhaled fluticasone propionate in patients with chronic obstructive pulmonary disease. Lancet 1998; 351: 773-780.

108 Calverley P, Pauwels R, Vestbo J, et al. Combined salmeterol and fluticasone in the treatment of chronic obstructive pulmonary disease: a randomised controlled trial. Lancet 2003; 361: 449-456.

109 Davies MJ, Fuller P, Picciotto A, et al. Persistent nocturnal cough: randomised controlled trial of high dose inhaled corticosteroid. Arch Dis Child 1999; 81: 38-44.

110 Chang $\mathrm{AB}$, Phelan $\mathrm{PD}$, Carlin JB, et al. A randomised, placebo controlled trial of inhaled salbutamol and beclomethasone for recurrent cough. Arch Dis Child 1998; 79: 6-11.

111 Dicpinigaitis PV, Dobkin JB, Reichel J. Antitussive effect of the leukotriene receptor antagonist zafirlukast in subjects with cough-variant asthma. J Asthma 2002; 39: 291-297.

112 Spector SL, Tan RA. Effectiveness of montelukast in the treatment of cough variant asthma. Ann Allergy Asthma Immunol 2004; 93: 232-236.

113 Kita T, Fujimura M, Ogawa H, et al. Antitussive effects of the leukotriene receptor antagonist montelukast in patients with cough variant asthma and atopic cough. Allergol Int 2010; 59: 185-192.

114 Benard B, Bastien V, Vinet B, et al. Neuropsychiatric adverse drug reactions in children initiated on montelukast in real-life practice. Eur Respir J 2017; 50: 1700148.

115 Faruqi S, Molyneux ID, Fathi $\mathrm{H}$, et al. Chronic cough and esomeprazole: a double-blind placebo-controlled parallel study. Respirology 2011; 16: 1150-1156.

116 Shaheen NJ, Crockett SD, Bright SD, et al. Randomised clinical trial: high-dose acid suppression for chronic cough - a double-blind, placebo-controlled study. Aliment Pharmacol Ther 2011; 33: 225-234.

117 Giuliano C, Wilhelm SM, Kale-Pradhan PB. Are proton pump inhibitors associated with the development of community-acquired pneumonia? A meta-analysis. Expert Rev Clin Pharmacol 2012; 5: 337-344.

118 Moayyedi P, Leontiadis GI. The risks of PPI therapy. Nat Rev Gastroenterol Hepatol 2012; 9: 132-139.

119 Berkhof FF, Doornewaard-ten Hertog NE, Uil SM, et al. Azithromycin and cough-specific health status in patients with chronic obstructive pulmonary disease and chronic cough: a randomised controlled trial. Respir Res 2013; 14: 125

120 Yousaf N, Monteiro W, Parker D, et al. Long-term low-dose erythromycin in patients with unexplained chronic cough: a double-blind placebo controlled trial. Thorax 2010; 65: 1107-1110.

121 Hodgson D, Anderson J, Reynolds C, et al. The effects of azithromycin in treatment-resistant cough: a randomized, double-blind, placebo-controlled trial. Chest 2016; 149: 1052-1060.

122 Ryan NM, Birring SS, Gibson PG. Gabapentin for refractory chronic cough: a randomised, double-blind, placebo-controlled trial. Lancet 2012; 380: 1583-1589.

123 Vertigan AE, Kapela SL, Ryan NM, et al. Pregabalin and speech pathology combination therapy for refractory chronic cough: a randomized controlled trial. Chest 2016; 149: 639-648.

124 Zaccara G, Giovannelli F, Giorgi FS, et al. Tolerability of new antiepileptic drugs: a network meta-analysis. Eur J Clin Pharmacol 2017; 73: 811-817.

125 Gardiner SJ, Chang AB, Marchant JM, et al. Codeine versus placebo for chronic cough in children. Cochrane Database Syst Rev 2016; 7: CD011914.

126 Vertigan AE, Theodoros DG, Gibson PG, et al. Efficacy of speech pathology management for chronic cough: a randomised placebo controlled trial of treatment efficacy. Thorax 2006; 61: 1065-1069.

127 Chamberlain Mitchell SAF, Garrod R, Clark L, et al. Physiotherapy, and speech and language therapy intervention for patients with refractory chronic cough: a multicentre randomised control trial. Thorax 2017; 72: 129-136.

128 Marchant J, Masters IB, Champion A, et al. Randomised controlled trial of amoxycillin clavulanate in children with chronic wet cough. Thorax 2012; 67: 689-693.

129 Ternesten-Hasséus E, Johansson EL, Millqvist E. Cough reduction using capsaicin. Respir Med 2015; 109: 27-37.

130 Belvisi MG, Birrell MA, Wortley MA, et al. XEN-D0501, a novel transient receptor potential vanilloid 1 antagonist, does not reduce cough in patients with refractory cough. Am J Respir Crit Care Med 2017; 196: $1255-1263$.

131 Morice AH. TRPA1 receptors in chronic cough. Pulm Pharmacol Ther 2017; 47: 42-44.

132 Abdulqawi R, Dockry R, Holt $\mathrm{K}$, et al. P2X3 receptor antagonist (AF-219) in refractory chronic cough: a randomised, double-blind, placebo-controlled phase 2 study. Lancet 2015; 385: 1198-1205.

133 Smith AD, Cowan JO, Brassett KP, et al. Use of exhaled nitric oxide measurements to guide treatment in chronic asthma. N Engl J Med 2005; 352: 2163-2173.

134 Price DB, Buhl $\mathrm{R}$, Chan $\mathrm{A}$, et al. Fractional exhaled nitric oxide as a predictor of response to inhaled corticosteroids in patients with non-specific respiratory symptoms and insignificant bronchodilator reversibility: a randomised controlled trial. Lancet Respir Med 2018; 6: 29-39.

135 Cheng S-L. Blood eosinophils and inhaled corticosteroids in patients with COPD: systematic review and meta-analysis. Int J Chron Obstruct Pulmon Dis 2018; 13: 2775-2784.

136 Mertens V, Blondeau K, Pauwels A, et al. Azithromycin reduces gastroesophageal reflux and aspiration in lung transplant recipients. Dig Dis Sci 2009; 54: 972-979. 